\title{
Collaborative conservation helps achieve regional water-quantity goals
}

\author{
T and and water conservation in places \\ Luch as coastal California, which
} is almost entirely comprised of private land, cannot occur without landowner participation. We are engaged in a collaborative conservation process with a public interest group called the Salmon Coalition, to facilitate landowner participation in transformative restoration. This coalition represents a growing demand for more adaptive local approaches to resource management.

The Salmon Coalition was formed in 2006 to increase communication among the private landowners of Dry Creek, Knights and Alexander valleys (northern Sonoma County); resource agency staff (the National Oceanic and Atmospheric Administration and the California Department of Fish and Game); the Sonoma County Water Agency and their urban clients (nine water districts in Sonoma and Marin counties); environmental interest groups; and other stakeholders. Its goal is to set restoration priorities for salmon recovery while protecting and hopefully improving water security for rural and urban uses, and providing certainty to private landowners dealing with the federal Endangered Species Act (ESA). The coalition is an example of a policy-based initiative that utilizes stakeholder participation to design plans intended to protect habitat as compensation for regulatory protection against potential ESA violations (Cestero 1999).

Collaborative conservation is increasingly popular as decision authority on how to implement species recovery devolves from government to public stakeholders. An increased emphasis on farmer participation in water management planning is now part of the 2008 Farm Bill. The Agriculture Water Enhancement Program changes existing ground- and surface-water conservation programs to allow cooperative agreements between the Secretary of Agriculture, multiple producers, government entities and tribes, with $\$ 70$ million for each of fiscal years 2008 through 2012. Collaborative conservation will provide the basis for these agreements.
The outcomes of collaborative conservation are generally untested. In an attempt to define a common language and share lessons from case studies, a Sonoran Institute report called "Beyond the Hundreth Meeting" focused on public land issues, offering guidelines for improving the success of public planning processes (Cestero 1999). Place- or community-based efforts are distinguished from those that address a specific policy or interest-based initiatives, like the Salmon Coalition.

Cestero (1999) also reports that place-based efforts work best if they are led by local participants rather than government representatives, and take place in an open and inclusive process that can accommodate a full range of perspectives - including government representatives. It is also better if participants do not try to represent larger interest groups, because confusion can arise when individuals are held accountable for the larger, diverse group, some of whom will feel their interests were not well represented. In addition to completing the desired projects, collaborative conservation increases capacity among community residents to respond to external and internal stresses that will inevitably arise. This capacity can help prevent future problems from becoming crises.

Collaborative conservation groups that focus on smaller areas are more likely to succeed, because those involved can relate to the landscape in question and regular participation from people spread across a large geographic area is not required (Cestero 1999). The Quincy Library Group in Northern California, for example, was a group of approximately 30 people who developed a plan for 2.5 million acres of public forestland. Ultimately, the plan did not adequately address the diverse interests represented in this large and relatively populated area (Duane 1997). Such larger-scale conservation projects are better addressed through a network of local efforts (Cestero 1999).

The Salmon Coalition is primarily focused on two subwatersheds within the Russian River. Equally important, the

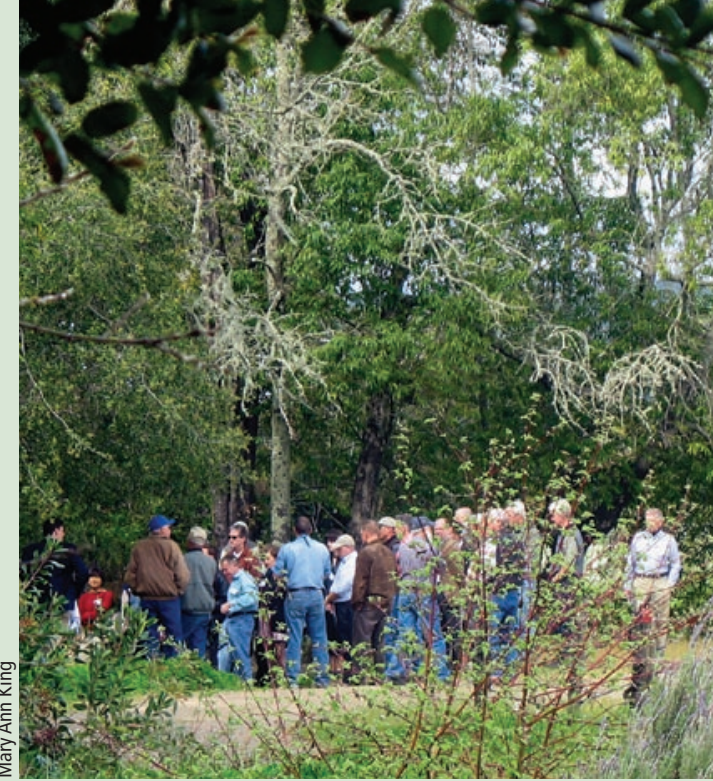

The Salmon Coalition and Trout Unlimited hosted a "Water and Wine" field tour.

Salmon Coalition has agreed to a participatory research effort that will greatly increase understanding of the various ways that water is managed across private lands. One way to empower a group early on is to begin collecting and evaluating existing information to increase understanding of the system (Cestero 1999). Wine-grape growers are providing us with information on water management practices, and private landowners will provide access for further stream-flow monitoring. Without this cooperation, local information could not be collected and we would continue to rely on coarse assumptions and management models that are ill-suited for such a complex system. The data will enhance our understanding of human-ecosystem interactions - a necessary step to better inform future water management and policy decision-making.

We intend for these efforts to help the State and local stakeholders resolve problems over additional requests for appropriative rights to store more water during the rainy season. Our data analysis and models will also be used by Sonoma County to improve its estimates of available flows for ecological processes (including enhancing salmonid recovery efforts) and municipal uses.

- A.M. Merenlender

\section{References}

Cestero, B. 1999. Beyond the Hundreth Meeting: A Field Guide to Collaborative Conservation on the West's Public Lands. Sonoran Institute. Tucson, AZ. 81 p.

Duane TP. 1997 Community participation in ecosystem management. Ecol Law Q 24:771-96. 